\title{
Notes on the vocalizations of Philippine Tailorbird (Orthotomus castaneiceps)
}

Peter Boesman

In the following we briefly analyze and compare voice of the different races of Philippine Tailorbird (Orthotomus castaneiceps). We also try to quantify the extent of any vocal differences using the criteria proposed by Tobias et al. (2010), as a support for taxonomic review. We have made use of sound recordings available on-line from Xeno Canto (XC).

Comparison of songs of the different races:
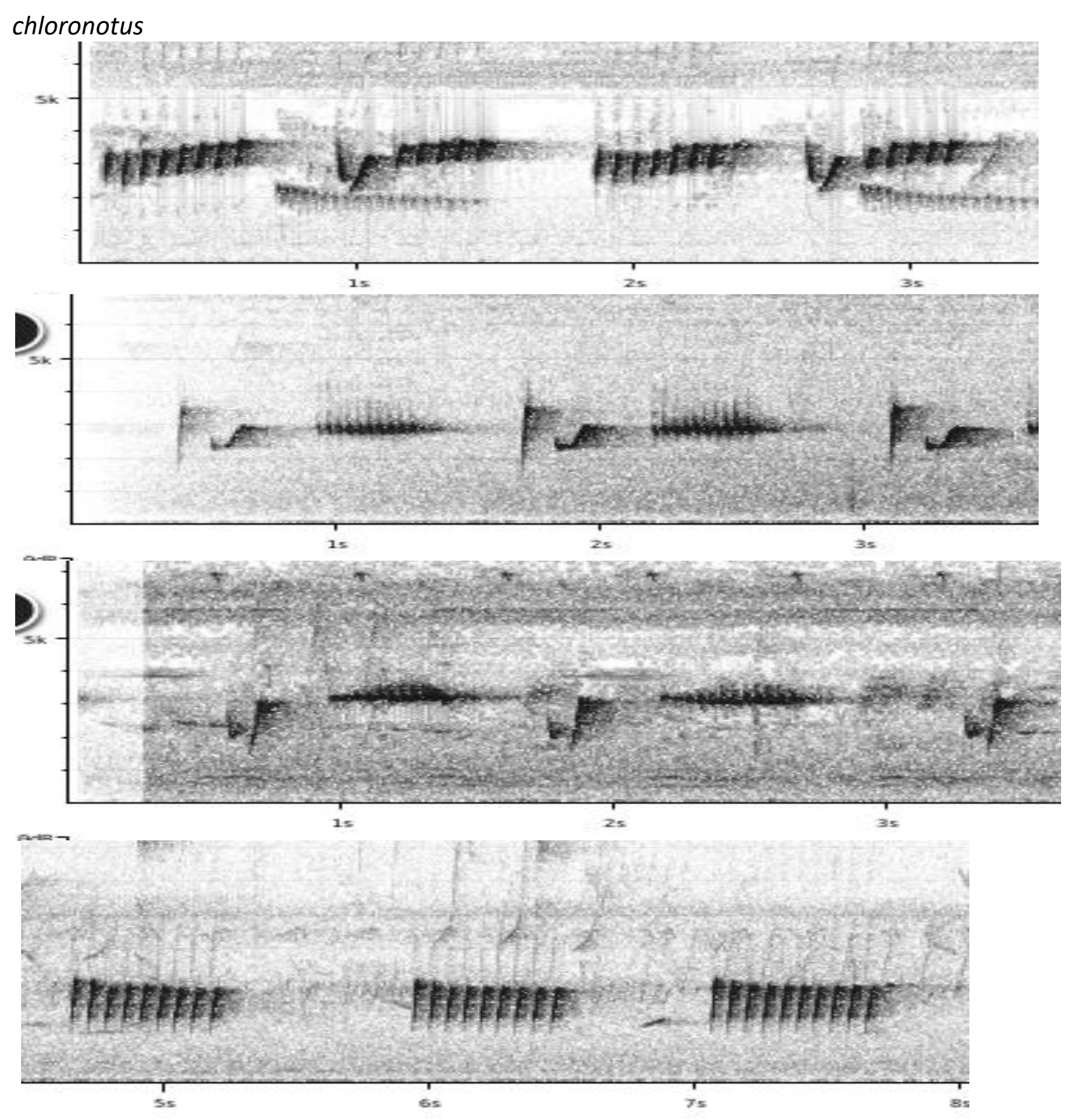


\section{HANDBOOK OF THE \\ Alve}

\section{ORNITHOLOGICAL NOTES}

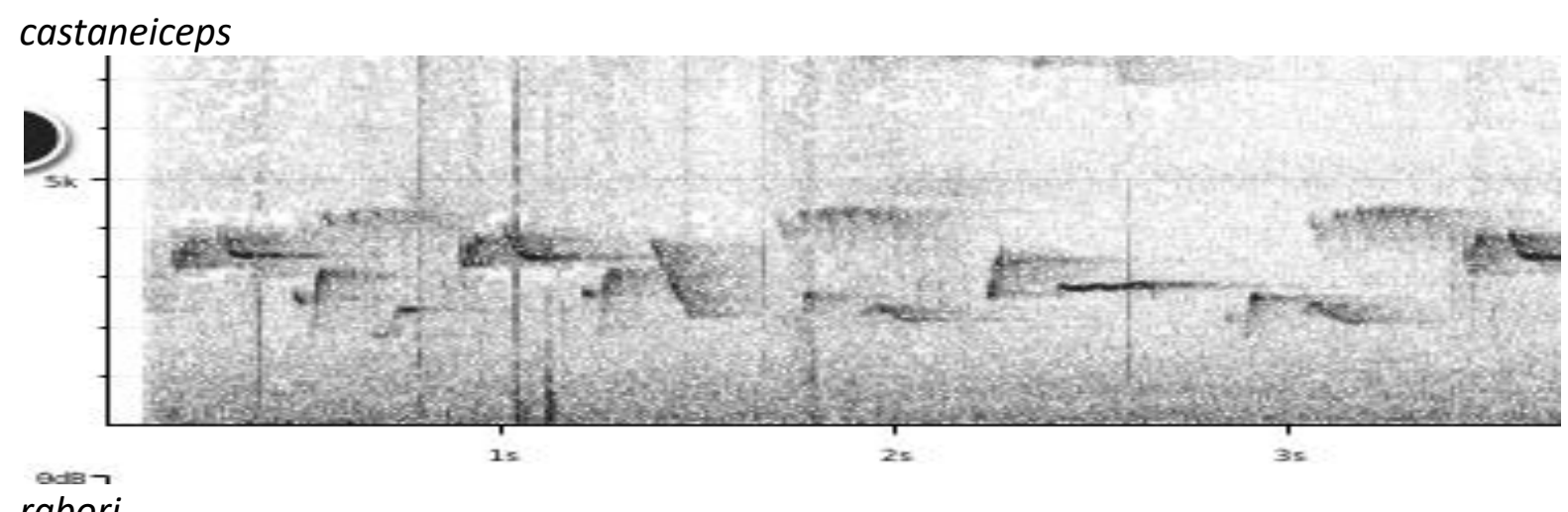

rabori
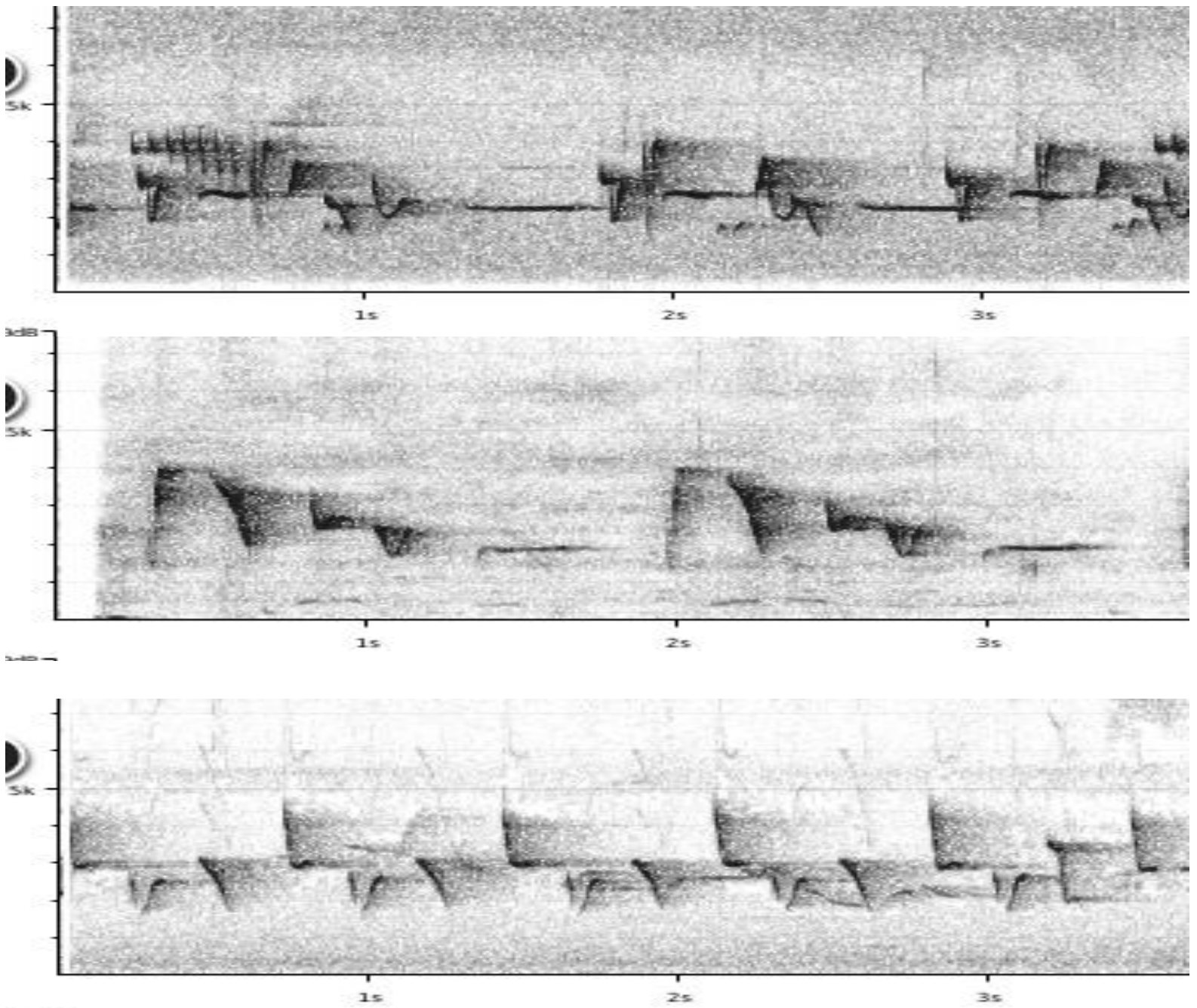

While vocal difference of chloronotus vs others is not as clear-cut as "trilled songs vs. not trilled song", differences are nevertheless quite obvious (from the limited number of recordings available):

chloronotus uses trills in about all its songs, these are typically preceded by just one or two notes. These trills are loud, consist of some 5-10 emphasized notes with a total length of about 0.5-0.8s. 


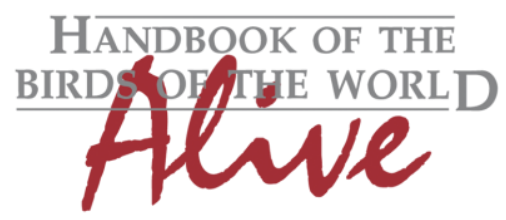

\section{ORNITHOLOGICAL NOTES}

castaneiceps/rabori only utters trills occasionally, these are rather weak, 5-7 notes, and fairly short at c. 0.4s. More importantly, these may well be uttered by the female bird, as part of an asynchronous duet, and thus possibly are not at all part of the male song (compare e.g. with first sonogram example of chloronotus where also another bird is superposing a trill on the male (trilled) song).

Based on these vocal differences, number of notes in a phrase (2-3) and maximum pace (2), or presence/absence of trill in male song, a total vocal score of at least 4 can be given.

There is another Orthotomus taxon on Luzon: O. derbianus. How does this one vocally compare with above two groups?

Examples of song:

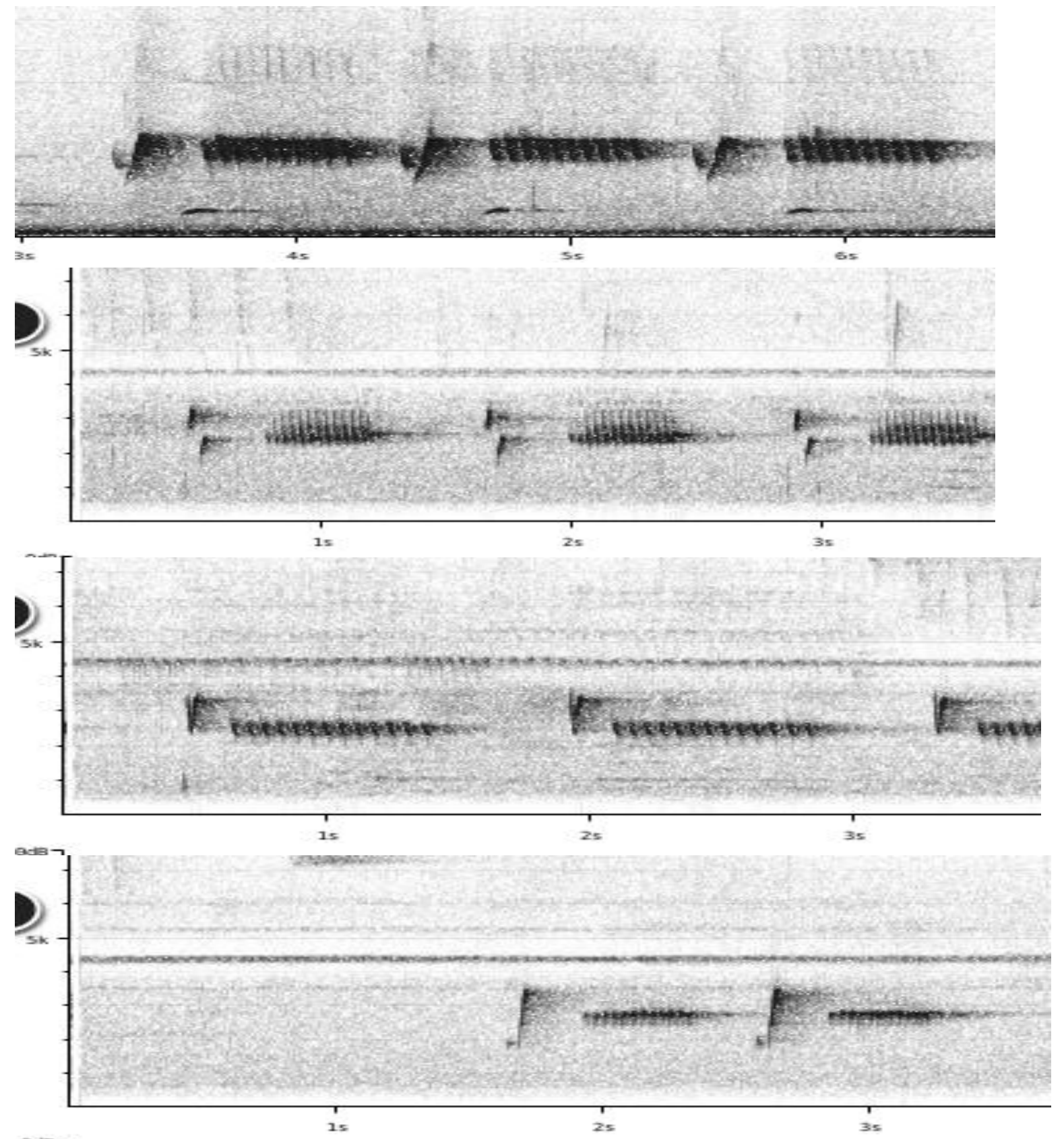




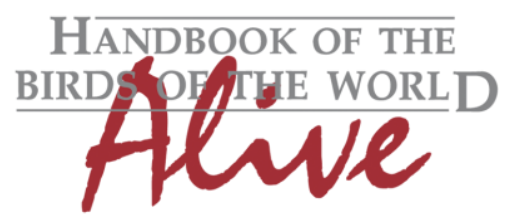

\section{ORNITHOLOGICAL NOTES}

This song is clearly of the same type as chloronotus: one or two intro notes followed by a trill. It would seem that the trill in derbianus is slightly lower-pitched than in chloronotus (typically below $3 \mathrm{kHz}$ vs. typically reaching above $3 \mathrm{kHz}$, with some overlap).

Without going into further detail, it is clear that score vs. castaneiceps/rabori is as high as in the above case for chloronotus: 4-5, while vocal score of derbianus vs. chloronotus at the other hand is tentatively only 1-2.

Finally, there is also $O$. frontalis of the southern islands with which to compare:

Examples of typical song:
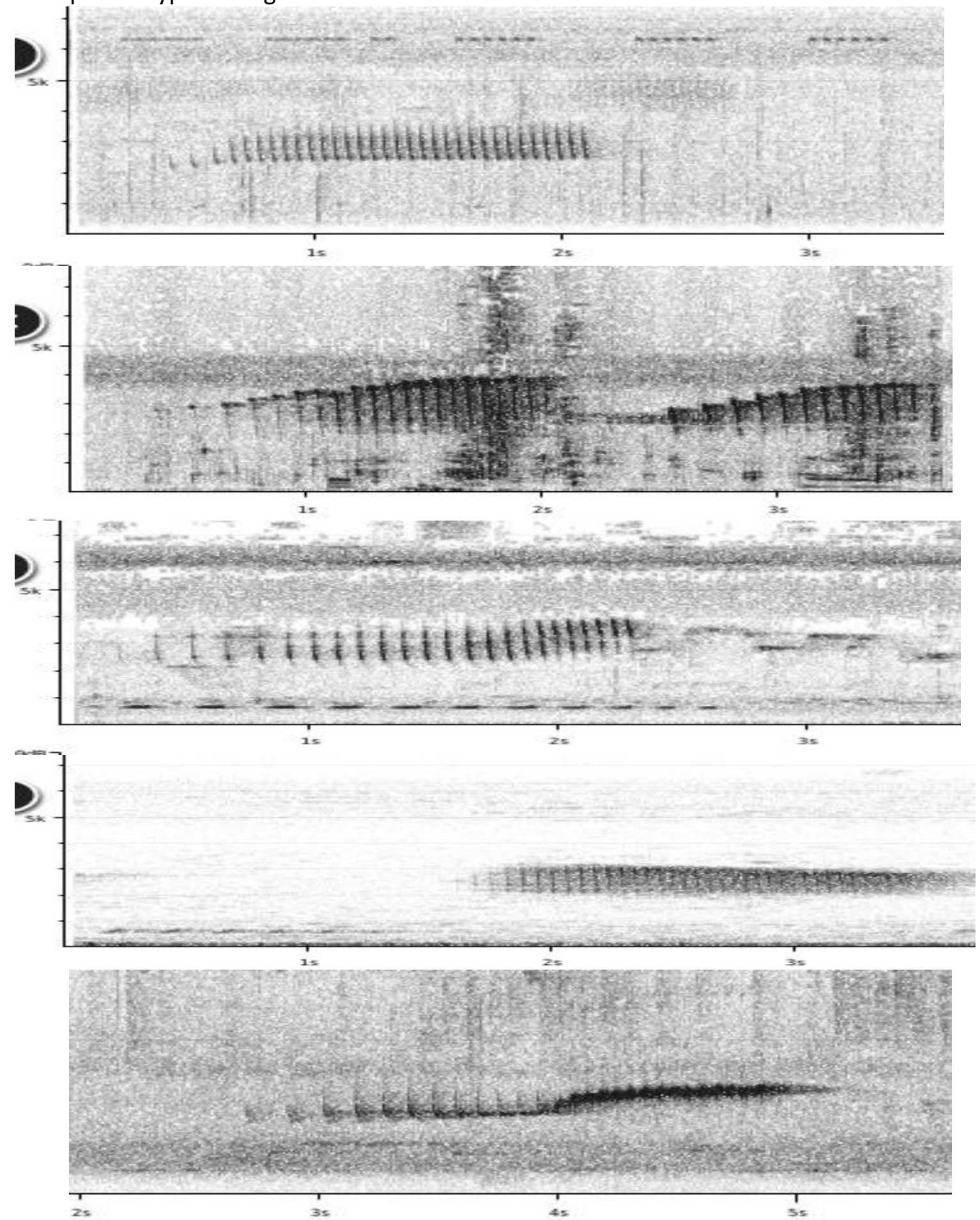

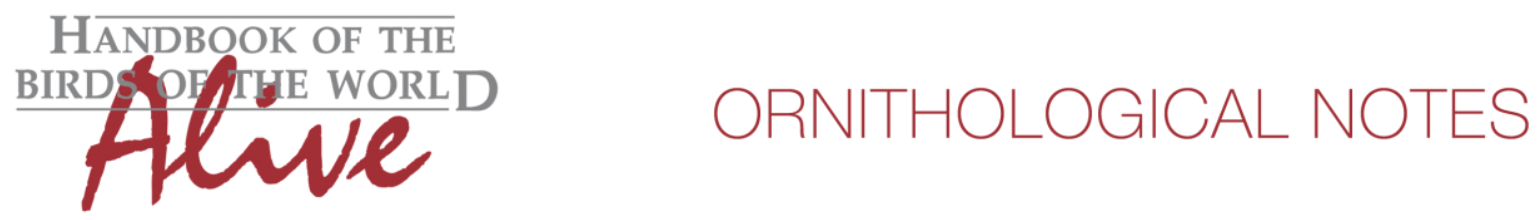

Song is a long rattling series which typically accelerates in pace and slightly increases in pitch. In all cases, rattle is at least $1.5 \mathrm{~s}$ long. This is clearly different from all other groups treated above. In comparison with chloronotus, the much longer trill (score 3), lack of clear introductory note (score 1-2), accelerating pace (score 1-2) and number of notes (score 2-3) lead to a total score of about 5-6.

In comparison with castaneiceps/rabori, vocal difference is even more obvious as not really comparable, but could be scored based on number of different notes (3), number of notes per phrase (3), average pace (3), leading to a total vocal score of 6.

This note was finalized on 17th February 2016, using sound recordings available on-line at that moment. We would like to thank in particular the sound recordists who placed their recordings for this species on XC: Desmond Allen, Oscar Campbell, Tomas Carlberg, Stijn de Win, Niels Poul Dreyer, David Edwards, Frank Lambert, Mike Nelson, Paul Noakes, Brendan Sloan, George Wagner and Ding Li Yong.

\section{References}

Tobias, J.A., Seddon, N., Spottiswoode, C.N., Pilgrim, J.D., Fishpool, L.D.C. \& Collar, N.J. (2010). Quantitative criteria for species delimitation. Ibis 152(4): 724-746.

\section{Recommended citation}

Boesman, P. (2016). Notes on the vocalizations of Philippine Tailorbird (Orthotomus castaneiceps). HBW Alive Ornithological Note 231. In: Handbook of the Birds of the World Alive. Lynx Edicions, Barcelona. (retrieved from http://www.hbw.com/node/932192 on 28 September 2016). 